\title{
A Morphological Study on Gross Anatomical Variations of Embalmed Cadaveric Livers
}

\section{Aliya Zahid ${ }^{1}$, Brishna Khan', Saira Munawar ${ }^{3}$}

\begin{abstract}
Objective: To find out gross anatomical variations of embalmed cadaveric livers.

Methods: Present study was conducted in dissection halls of Anatomy departments of Allama Iqbal Medical College, Lahore, Sahiwal Medical College, Sahiwal and Fatima Jinnah Medical University, Lahore during 2016-2019. In this study, 74 livers were dissected out from embalmed cadavers and preserved in 10\% formalin. Different morphological variations were observed in livers which included presence of accessory lobes, accessory sulci, notches, changes in size and shape of lobes. Liver specimens were photographed and classified according to Netter's classification of morphological variations of liver.

Results: The hepatic morphological variations observed included accessory fissures in the right, left, caudate and quadrate lobes of the liver, accessory lobes, elongated left lobe, hypoplastic left lobe, multiple deep diaphragmatic sulci, pons hepatis, Reidel's lobe, notched borders and bilobed caudate lobe.

Conclusion: The knowledge of various variations in morphology of cadaveric livers may help the radiologists to make accurate interpretation of the radiological images, thus minimizing the chances of incorrect reporting. It may also be helpful to the hepatobiliary surgeons to be aware of the morphological variations on the liver surface to avoid surgical complications.
\end{abstract}

Key Words: Embalmed cadaveric livers, accessory lobes, accessory fissures

\section{Introduction}

$\mathrm{T}$ he liver is the largest gland in the body and occupies the right hypochondrium, epigastrium, and left hypochondrium regions of abdomen. The liver is about $2 \%$ of body weight in the adults, which amounts to approximately 1800 gms in males and 1400 gms in females. The liver has a homogenous parenchyma and is divided into four anatomical lobes by peritoneal ligaments. Externally, falciform ligament divides the liver into a larger right lobe and a smaller left lobe. ${ }^{1}$ Caudate and quadrate lobes may be considered as the parts of the right anatomical lobe. ${ }^{2}$

\footnotetext{
1. Aliya Zahid

3. Saira Munawar

2. Brishna Khan

1,3. Anatomy Department, Fatima Jinnah Medical University, Lahore

2. Anatomy Department, Al-Aleem Medical College, Lahore
}

\section{Correspondence:}

Prof. Dr. Aliya Zahid

Head of Department of Anatomy, Fatima Jinnah Medical University, Lahore

Submission Date: 1st Revision Date: Acceptance Date:
17-07-2020

$16-09-2020$

30-09-2020
In 1897, Sir James Cantlie described the liver division between the right and left lobes. Later, Claude Couinaud (a French surgeon and anatomist) provided additional insight and described the segments of liver based on hepatic vasculature. According to Couinaud classification, the liver is divided into 8 functionally independent segments having their own blood inflow, outflow and biliary drainage. In the center of each segment, a branch of the portal vein, hepatic artery and bile duct is present. These fundamental studies provided a basic framework for surgical discussions of liver anatomy. ${ }^{3}$ The peritoneum normally invaginates into the parenchyma of liver forming sulci and fissures. There are four normal fissures in human liver: fissures for the ligamentum venosum, ligamentum teres, and gallbladder and the transverse fissure. ${ }^{4}$

Liver development begins during 3rd week of intrauterine life. Liver parenchyma is derived from the endoderm of the foregut, whereas the stroma is derived from the mesoderm. The hepatic diverticulum is derived from the caudal part of foregut, that grows into the septum transversum, which is a splanchnic mesodermal mass which extends between the heart anlage and the mesentery. Septum transver- 
sum and cardiac mesoderm have inductive influence for the development of hepatic diverticulum. Stromal tissue of the liver develops from the septum transversum and splanchnic mesoderm around gut. Septum transversum hence divides the developing organ into lobes and lobules making the connective tissue parts of the liver. Initially the development of the liver lobes is symmetric. As the development continues, the growth of the right lobe accelerates and it is difficult for the left lobe of liver to find adequate space due to progressively developing gut. ${ }^{5-10}$

Congenital hepatic anomalies are caused due to defective development or excessive development of the liver. Defective development of the left liver lobe may lead to gastric volvulus while defective development of the right lobe either leads to portal hypertension or remains clinically latent. Anomalies related to excessive development of the liver lead to formation of accessory lobes of liver. In most cases, the accessory liver lobe is found in the infra-hepatic position. Riedel's lobe is one of the best-known examples of a sessile accessory liver lobe. ${ }^{11}$ Torsion is common in few cases where the accessory lobe has a pedicle. While accessory lobes can simulate tumors, there have also been some reports of hepatocellular tumor. ${ }^{12}$ Riedel's lobe corresponds to hypertrophy of segments V and VI. It was first described by Corbin in 1830 and defined by Riedel in 1888 as a "round tumor on the anterior side of the liver, the gallbladder, to its right". The prevalence of Riedel's lobe ranges from $3.3-31 \%$, with a higher incidence in women than in men. $^{13-15}$

\section{Methods}

Present study was conducted in dissection halls of Anatomy departments of Allama Iqbal Medical College, Lahore, Sahiwal Medical College, Sahiwal and Fatima Jinnah Medical University, Lahore during 2016-2019. In this study, 74 livers were dissected out from the embalmed cadavers and preserved in formalin. Morphological variations such as changes in shape and size of right, left, caudate and quadrate lobes, presence of accessory lobes, accessory sulci, abnormal processes and notches on right, superior and inferior borders of livers were noted. Porta hepatis, fossa for gall bladder, grooves for ligamentum teres \& ligamentum venosum were also observed for any variation. Livers were photographed and classified according to Netter's classification of morphological variations of liver.

\section{Results}

In the present study of the 74 liver specimens, 36 livers $(48.6 \%)$ were observed with normal surfaces,

Table 1: Table 1. Netter's Classification of Morphological Variations of liver ${ }^{16}$

\begin{tabular}{cl}
\hline Types & \multicolumn{1}{c}{ Description } \\
\hline Type 1 & Normal \\
Type 2 & Very small left lobe, deep costal impressions \\
Type 3 & Complete atrophy of left lobe \\
Type 4 & Transverse saddle like liver, relatively large left lobe \\
Type 5 & Tongue like process of right lobe \\
Type 6 & Very deep renal impression and corset constriction \\
Type 7 & Diaphragmatic grooves \\
\hline
\end{tabular}

fissures, and borders without any additional accessory fissures or malformations. Of the remaining 38 specimens, hepatic surface variations were documented and broadly grouped as having accessory fissures, accessory lobes, presence of a pons hepatis, notching of borders.

Of the superior sulci, 4 appeared to have deep multiple diaphragmatic grooves, one of liver also had hypoplastic left lobe (Fig 1). 10 livers were noted to have accessory fissures on the right, left, caudate and quadrate lobes (Figs. 2,3,4 and 5). Accessory lobes were identified on 8 specimens (10.9\%). Pons hepatis were seen in 2 specimens, (Fig. 2). Notching on superior border were observed in 5 specimens (Fig 2,3)

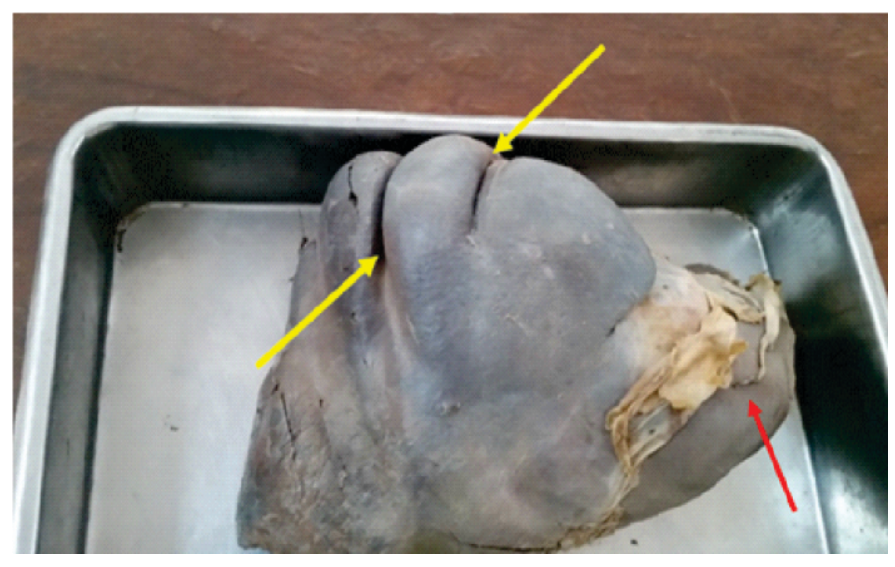

Fig.1: Yellow Arrows (Deep Costal Sulci, Netter Type 2), Red Arrow (Hypoplastic Left Lobe) 


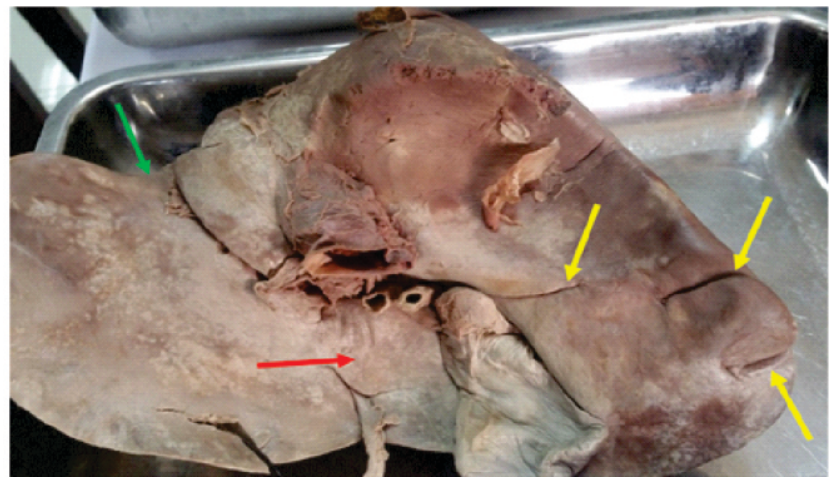

Fig.2: Green Arrow (Deep Notch on Superior border), Yellow Arrows (Accessory Sulci on Right lobe), RedArrow (Pons Hepatis)

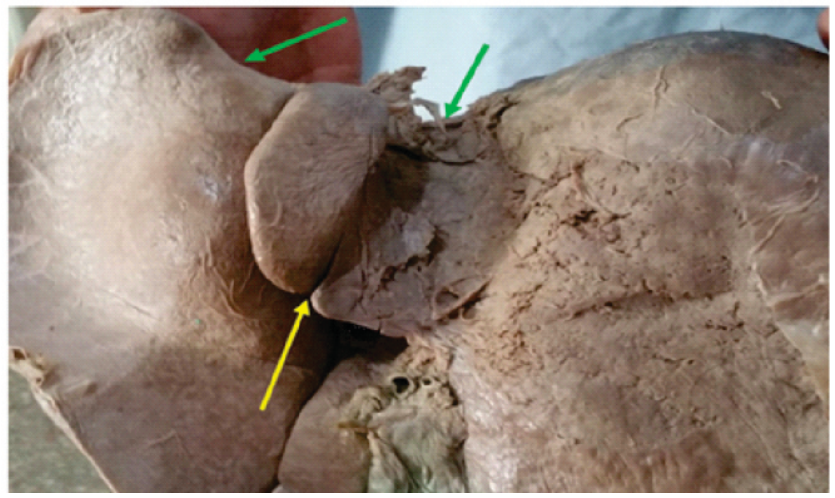

Fig.3: Green Arrows (Deep Notches on Superior Border), Yellow Arrow (Accessory Sulcus \& Bilobed Caudate Lobe)

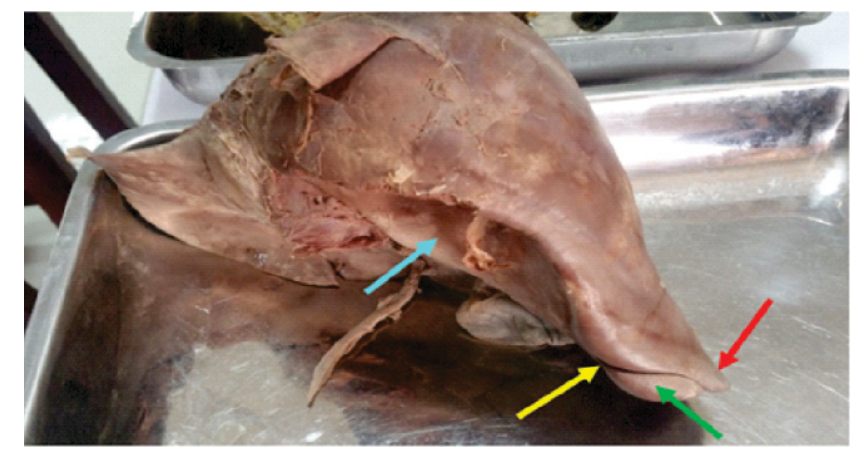

Fig.4: Red arrow (Tongue like Process of Right Lobe, Netter Type 5), Yellow Arrow (Accessory Sulcus), Green Arrow (Small Accessory Lobe), Blue Arrow (Deep Renal Impression)

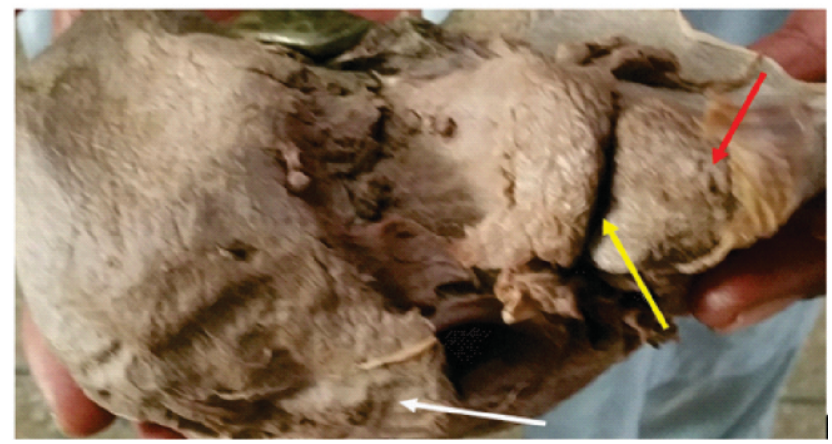

Fig.5: White Arrow (Transverse Saddle Type Liver,
Relatively Large Left Lobe, Netter Type 4), Yellow Arrow (Sulcus on Right Lobe), Red Arrow (Bilobed Small Right Lobe)

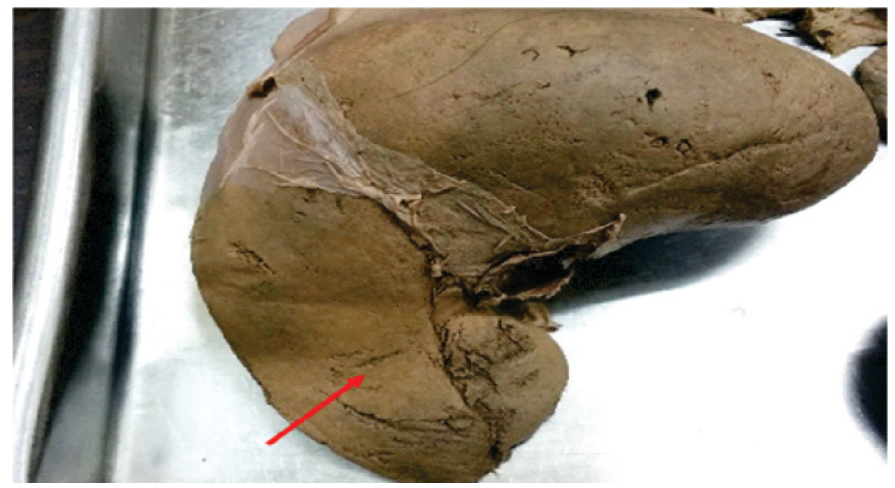

Fig.6: Red arrow (Lingular Process of Left Lobe)

Table 2: Gross artatomical Variation in Embalmed Cadaveric Livers

\begin{tabular}{clcc}
\hline $\begin{array}{c}\text { Sr } \\
\text { No }\end{array}$ & \multicolumn{1}{c}{ Variations } & $\begin{array}{c}\text { Number } \\
\text { of livers }\end{array}$ & Percentage \\
\hline 1 & Accessory lobes & 8 & $10.8 \%$ \\
2 & Accessory fissures & 10 & $13.5 \%$ \\
3 & Hypoplastic left lobes & 3 & $4 \%$ \\
4 & Reidel's lobe & 3 & $4 \%$ \\
5 & Lingular process of left lobe & 2 & $2.7 \%$ \\
6 & Notches on superior borders & 5 & $6.7 \%$ \\
7 & $\begin{array}{l}\text { Pons hepatis } \\
8\end{array}$ & 2 & $2.7 \%$ \\
Deep renal impression on right & 3 & $4 \%$ \\
9 & $\begin{array}{l}\text { lobe } \\
\text { Prominent and deep } \\
\text { diaphragmatic fissures on superior } \\
\text { surface of liver }\end{array}$ & 4 & $5.4 \%$ \\
\hline
\end{tabular}

\section{Discussion}

Hepatic anomalies and variations are caused due to defective development of the liver. In present study, accessory lobes and accessory fissures were found in $10.8 \%$ and $13.5 \%$ cases respectively. Nayak carried out a similar study in South Indian population. He studied 55 formalin fixed livers for presence of abnormal lobes, impressions, sulci and position of gall bladder. In his study, $60 \%$ of liver specimens were normal. $40 \%$ specimens showed variations of lobes and fissures. Accessory lobes were found in $9.09 \%$ of cases. ${ }^{17}$ In another study on 90 formalin fixed livers, Joshi and colleagues found abnormal shapes of the quadrate and caudate lobes. Accessory fissures were more common in the right lobe. In $18 \%$ livers, notching along the lower border of caudate lobe was observed, a longitudinal fissure was found in $30 \%$ liver specimens, and prominent papillary process was found in $32 \%$ of liver specimens. 
Presence of pons hepatis, bridging the left lobe and quadrate lobe, was observed in $30 \%$ of the livers observed. ${ }^{18}$ In present study, out of 74 livers studied, only $2(2.70 \%)$ livers showed pons hepatis. Pons hepatis was first identified by von Haller in 1743, as a segment of hepatic tissue connecting the quadrate lobe to the left lobe over fissure for ligamentum teres. In another study, the pons hepatis refers to hepatic tissue surrounding the inferior vena cava. ${ }^{19}$

Present study showed the presence of prominent diaphragmatic sulci on the superior surface of the liver in 5.4\% cases. Machi et al in their study observed the diaphragmatic sulci in the superior surface of the livers in $40 \%$ of cases at autopsy. All fissures were located in the right lobe of liver and in $47 \%$ specimens, they were multiple. These findings suggest that the pressure exerted by the diaphragm as a whole may be responsible for the formation of sulci at the level of weak zones, represented by the portal grooves. ${ }^{20}$ Another study on cadaveric livers showed variations in shape of the quadrate lobes with $40 \%$ being rectangular, $30 \%$ being pear-shaped, $20 \%$ being triangular and another $10 \%$ were square in shape. The presence of accessory fissures on the diaphragmatic surface of the liver were observed in $10 \%{ }^{21}$ In our study, 4 (5.4\%) liver specimens showed prominent and deep diaphragmatic fissures on superior surface of liver.

Gupta and colleagues observed that the liver surfaces have 1-3 sulci distributed on all lobes in 70\% liver specimens demarcating the vascular segments, which may help the surgeon during resection of liver. ${ }^{22}$ In another study, Othman et al studied 40 liver specimens and the presence of accessory fissures were evident in only 2 specimens $(5 \%)$. The accessory fissures were located in the inferior and posterior surfaces of the right lobes. ${ }^{23}$ In our study, $13.5 \%$ liver specimens had accessory sulci.

The liver can present a number of congenital anomalies. They include irregularities of the shape, impressions on the liver surface, number of lobes, the presence of accessory lobes and accessory fissures. ${ }^{24-26}$

\section{Conclusion}

Study of surface variations in morphology of liver can help the surgeons to dissect in proper surgical planes to make the resection safe. Clinicians, radiologists and surgeons should be aware of such morphological variations to prevent diagnostic and surgical misadventures.

\section{Author's Contribution}

AZ: Conceived the idea, wrote the manuscript

BK: Analysis of manuscript

SM: Interpreting the results and worked on manuscript

\section{References}

1. Sibulesky L.Normal liver anatomy. Clin Liver Dis (Hoboken). 2013 Mar; 2(Suppl 1): S1-S3.

2. Singh HR, Rabi S. Study of morphological variations of livers in humans. Translational research in Anatomy. 2019; 14:1-5.

3. Juza RM, Pauli EM. Clinical and surgical anatomy of the liver: a review for clinicians. Clin Anat .2014 Jul;27(5):764-9. doi: 10.1002/ca.22350.

4. Sagoo MG, Aland RC, Gosden E. Morphology and morphometry of the caudate lobe of the liver in two populations. Anat Sci Int. 2018;93(1):48-57. doi: 10.1007/s12565-016-0365-7

5. Esrefolu M, Taslidere E, Cetin A. Development of Liver and Pancreas. Bezmialem Science. 2017; 4: 305 DOI: $10.14235 /$ bs. 2016.841

6. Moore KL, Torchia MG. The developing human: clinically oriented embryology. 10th ed. Philadelphia: Elsevier; 2016.

7. Sadler TW. Langman's Medical Embryology. 14th ed. Philadelphia: Lippincott Williams \& Wilkins; 2019.

8. Larsen W. Development of the gastrointestinal tract. In: Sherman LS, Potter SS, Scott WJ, eds. Human Embryology, 3rd ed. Philadelphia: Churchill Living stone; 2001: 235-64.

9. Carslon BM. Human embryology and developmental biology. 4th. ed. Philadelphia: Mosby Elsevier; 2009.

10. Nayak SB, Kumar N, Sirasanagandla SR, Shetty SD. A mini accessory liver lobe in the fissure for ligamentum teres and its clinical significance: a case report. J Clin Diagn Res. 2013 Nov;7(11):2573-4.

11. Savopoulos C, Kakaletsis N, Kaiafa G, Iliadis F, Kalogera-Fountzila A, Hatzitolios AI. Riedel's lobe of the liver: a case report. Medicine (Baltimore). 2015;94(3):e430.

12. Glenisson M, Salloum C, Lim C, et al. Accessory liver lobes: anatomical description and clinical implications. Journal of Visceral Surgery. 2014 Dec; 151(6):451-455.

13. Lin J, Sumathilatha Velavan S. Hepatic morphology: 
variations and its clinical importance Justin Chin, Patrick O’Toole, Eur. J. Anat. 2018., 22 (3): 195-201.

14. Patil S, Sethi M, Kakar S. Morphological study of human liver and its importance. Int J Anat Res. 2014., 2(2): 310-314.

15. Dancygier $H$. Malformations and Malpositions of the Liver. In: Clinical Hepatology. 2010., Springer, Berlin, Heidelberg. https://doi.org/10.1007/978-3642-04519-6_1

16. Netter FH, Colacino S. Atlas of Human Anatomy. 6th ed. New York: Guilford Press; 2014.

17. Nayak, BS. A study on the anomalies of Liver in the South Indian cadavers. Int. J. Morphol.2013., 31(2): 658-661.

18. Joshi SD, Joshi SS, Athavale SA. Some interesting observations on the surface features of the liver and their clinical implications. Singapore Med J. 2009 Jul;50(7):715-9.

19. Reddy N, Joshi SS, Mittal PS, Joshi SD. Morphology of caudate and quadrate lobes of liver. J Evolution Med Dentl Sci, 2017., 6(11): 897-901.

20. Macchi V, Feltrin G, Parenti A, De Caro R. Diaphrag- matic sulci and portal fissures. J Anat. 2003 Mar; 202(Pt 3):303-8.

21. Choy KW, Kogilavani S, Norshalizah M, Rani S, Aspalilah A, Farihah HS, Faizah O, Norzana AG, Das S. Anomalous structures of the liver: an anatomical insight. Clin Ter. 2013 May-Jun;164(3):197-201.

22. Gupta M, Sodhi L, Yadav TD. Morphology of liver. Indian J Surg. 2008;70(1):3-7.

23. Othman FB, Latiff AA, Suhaimi FH, Das S. Accessory sulci of the liver. An anatomical study with clinical implications. Saudi Med J. 2008 Sep;29(9): 1247-9.

24. Pryakhin A. Accessory lobes, accessory fissures and prominent papillary process of the liver. Anat J Afr. 2015: 4(2): 611-616.

25. Chaudhari HJ, Ravat MK, Vaniya VH, Bhedi AN. Morphological Study of Human Liver and Its Surgical Importance. J Clin Diagn Res. 2017;11(6): AC09-AC12.

26. Wahane A, Satpute C. Normal morphological variations of liver lobes: A study on the adult human cadaveric liver in the Vidarbha Region. Int J Sci Res. 